\title{
EVALUATION OF PARENTAL SATISFACTION OF CHILDREN'S SPACES WITHIN HIGH RISE APARTMENT ENVIRONMENTS
}

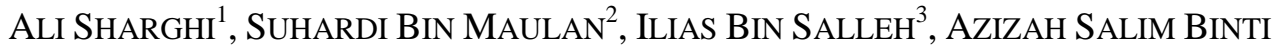 \\ SYED SALIM $^{4}$, BAHRAM SALEH SEDGHPOUR ${ }^{5}$
}

${ }^{I}$ Faculty of Design and Architecture, Universiti Putra Malaysia (UPM), Malaysia \& Lecturer in Shahid Rajaee Teacher Training University (SRTTU), Iran, Email: a_sharghi_a@yahoo.com

${ }^{2}$ Dr. of Landscape Architecture, Faculty of Design and Architecture, Universiti Putra Malaysia (UPM), Malaysia

${ }^{3}$ Professor of architecture, Faculty of Design and Architecture, Universiti Putra Malaysia (UPM), Malaysia

${ }^{4}$ Associate Professor of architecture, Faculty of Design and Architecture, Universiti Putra Malaysia (UPM), Malaysia

${ }^{5}$ Assistant Professor, Faculty of human science, Shahid Rajaee Teacher Training University (SRTTU), Iran

Received: $6^{\text {th }}$ May 2014, Accepted: $18^{\text {th }}$ August 2014

\begin{abstract}
In the design process of open spaces within residential apartments, little attention is paid to children and their attitude to the environment is often ignored. Children, especially those who live in high-rise apartments, were found to have less connection with nature. Children supposedly need to engage in physical activities within outdoor areas, but urban planners, with the approval of managers or parents, must adequately design the open space for children. This paper initially reviews different research in this area. It consequently attempts to evaluate parental satisfaction regarding children's connectivity to open spaces as a dependent variable, and their preferences and perception of safety as independent variables. The research method is based on a questionnaire survey addressed to 261 parents and adults, in two localities in Tehran, Iran. The result of this research shows that parental attitude to open space has an effect on children's outdoor activities. Moreover, parents with young children express lower satisfaction to open spaces than those adults without young children. Families with children need open spaces in residential high-rise apartments for their siblings' physical activities, and the designers should consider such an important need.
\end{abstract}

Keywords: Children, Parents, Open Space, Satisfaction, High-Rise Apartments

\section{INTRODUCTION}

The relationship between children and nature forms a fundamental part of development, which helps them achieve their full potential (Barbel, 2000). Participant perception regarding children playing outdoors has an important role in children's physical activities; it is a major aspect that impacts upon children's activities in open spaces. In comparison with adults, 
Sharghi, A., Maulan, S. B., Salleh, I. B., Salim, A. S. B S., Sedghpour, B. S.: Evaluation of Parental Satisfaction of Children's Spaces within High Rise Apartment Environments

physical activity in children has a different nature. In particular, children aged between 2 to 11 years old need far more physical activity than teenagers and adults; and almost all young people naturally display higher physical activity levels than adults (Rowlands \& Eston et al., 1999). In contrast, Veitch \& Salmon et al. (2008) showed that parents are concerned with their child's safety, route to the place of play, facilities at the playground, effect of space design on their perception of outdoor areas, and their decision of whether or not to allow children to play freely in an outdoor environment.

These concerns limit some places available for children to play. Children who live in secure communities were more likely to play independently and unsupervised by parents, because adults perceive that it is a safe place for their children to play (Veitch \& Salmon et al., 2008). Moreover, Valentine \& McKendrick (1997) argued that the most significant influence on children's access to independent play is parental anxiety about child safety. Furthermore, Carver \& Timperio et al., (2008) suggested that low levels of physical activity among children in their neighborhood are associated with parental satisfaction and perceived level of neighborhood safety. Weir \& Etelson et al. (2006) mentioned that children's physical activity levels in the city negatively affect parental anxiety on neighborhood safety, and their satisfaction about open space. Moreover, adults organise children's activities, and most children are no longer free to go to their neighborhoods unless accompanied by their parents (Weir \& Etelson et al., 2006).

Theoretically, satisfaction overall and also for open areas, has a variety of meanings that numerous theories such as: Hierarchy of Needs Theory (Maslow \& Frager et al., 1970) and Cognitive Evaluation Theory (Deci \& Koestner et al., 1999) discussed, term of this variety for people satisfaction regarding places or environments. Most of these theories relate to people's behavior in job-related or educational areas; while this study concentrates on one of them that is more related to residents' satisfaction concerning their home areas. This view relates to Maslow's hierarchy of need theory (Maslow \& Frager et al., 1970).

In addition, Maslow's theory provides several layers of motivational influences because human motivation is driven by a set of requests. These needs are arranged in a fundamental hierarchy. When the basic needs are satisfied, the individual seeks higher needs. There is overlap, as that's when the basic needs are satisfied and the higher needs can become a motivator. The fundamental needs must be satisfied before that next level of needs become motivators (Gordon, 2009). This theory is studied in many areas, for instance, Yang (2012) applied it in principle on street design as: legible, accessible, comfort and safety, and explains how these impact people's satisfaction to use and enjoy their local neighborhoods. Mnisi-Mudunungu (2011) also used it for studying the satisfaction regarding safety and shelter as a need in a home's environment for residents.

Therefore, it is important to understand the parental satisfaction of open spaces of high-rise apartments regarding children's connection to outdoor environments, because, according to Gifford (2007), high-rises are less satisfactory than other forms of housing for parents of small children. Gifford also stated it is difficult to find evidence showing high-rises are good for children (Gifford, 2007). Parental satisfaction from open spaces has an important role in supporting children's involvement in outdoor activities (Bringolf-Isler \& Grize et al., 2010).

It is hoped findings of this study fill the gaps between understanding of the relationships between parental satisfaction and children's connection to the environment. Mastura, Noorliza et al. (2008) stated that the factors making parents satisfied or dissatisfied with residential areas for their children are many. However, this study is focused on preferences and safety as independent variables which impact upon parental satisfaction regarding children connectivity to open spaces, because those are important factors in this aspect 
(Hagerhall, 2000; Purcell \& Peron et al., 2001; Ryan, 2006; Alton \& Adab et al., 2007; Melichar \& Kaprová, 2013).

As mentioned earlier, parental satisfaction has an important role in the physical activities of children. The aim of this study is to investigate parental satisfaction regarding open space in high-rise apartment complexes, because children in high-rises appear to have limited access and opportunities for going to open spaces, compared to children in non-high-rises.

In this study, parental satisfaction with open spaces in high-rise apartments regarding soft landscapes, children's playgrounds, recreation spaces and social spaces within open space, are discussed. Consequently, the relationship of parental satisfaction was tested with preferences for landscape elements and perception of safety in open spaces.

Specifically, the paper is seeking to answer the following questions:

a) What are the parental satisfactions for open space associated with high-rise apartments?

b) How does parental satisfaction relate to:

1. Perceived safety in their open space

2. Preferences for landscape elements

To answer those questions, a survey questionnaire method was used to gauge parental satisfaction for high-rise open spaces from two locations.

\section{STUDY METHODOLOGY}

\section{Survey Instruments}

This research focused on parents and adults that live in high-rise apartments, and their satisfaction for open spaces. The data was collected using a survey questionnaire, which is a useful method of data collection combining methods such as interviews, focus groups, tests and observation (Tashakkori \& Teddlie, 2003).

In order to measure satisfaction, using 13 variables/factors parents were asked to what extent they are satisfied with their current residential complex open space facilities and features. In addition, they were asked to answer two open-ended questions about things they like/dislike about their condominium open space. These open-ended questions can help to understand the things participants favoured or disliked about the open spaces of their condominium, that they could have forgotten to note in the closed-ended questions.

Furthermore, in order to measure parents' preferences regarding the open spaces facilities, they were asked about the facilities they prefer to have within open spaces using 11 variables and an open-ended question. In addition, parents were asked to indicate their opinion regarding their perception for the safety of children in their open spaces, through nine variables and an open-ended question about one thing that they do not like about their apartment's open space.

The data collected was analysed by using Statistical Package for Social Science (SPSS) Windows package version 2.0, in which the data was tabulated and analysed for normality, description and relations among variables. 


\section{Fig. 1: Site of Sobhan High Rise Apartments and its location in Tehran}

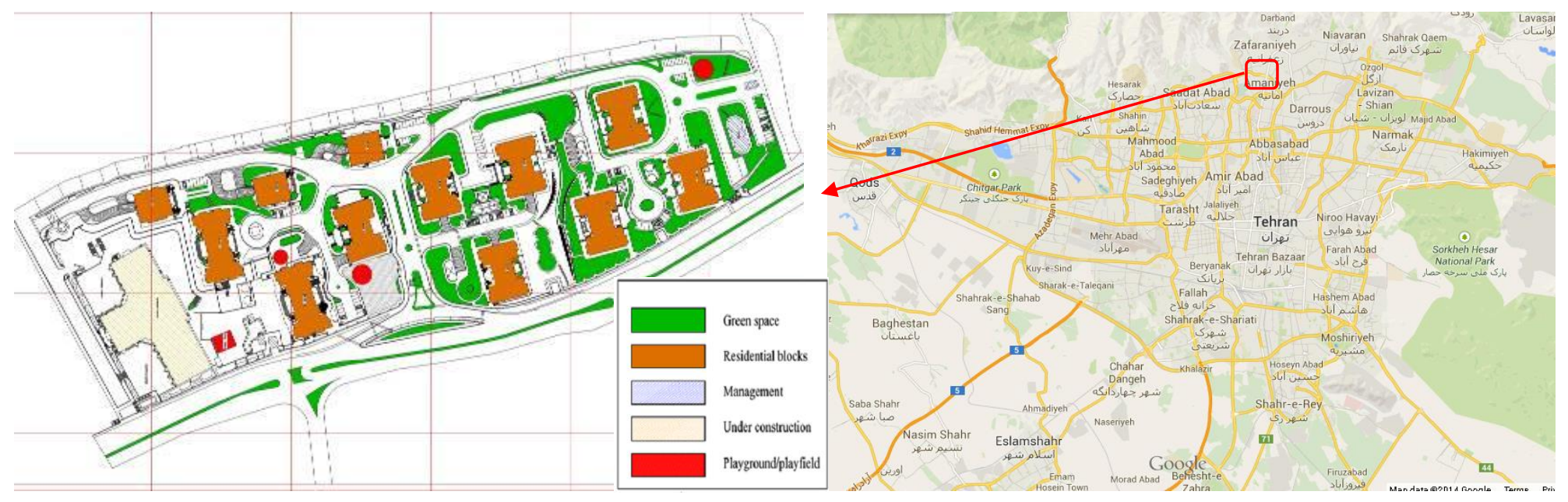

Fig. 2: Site of Pas High Rise Apartments and its location in Tehran

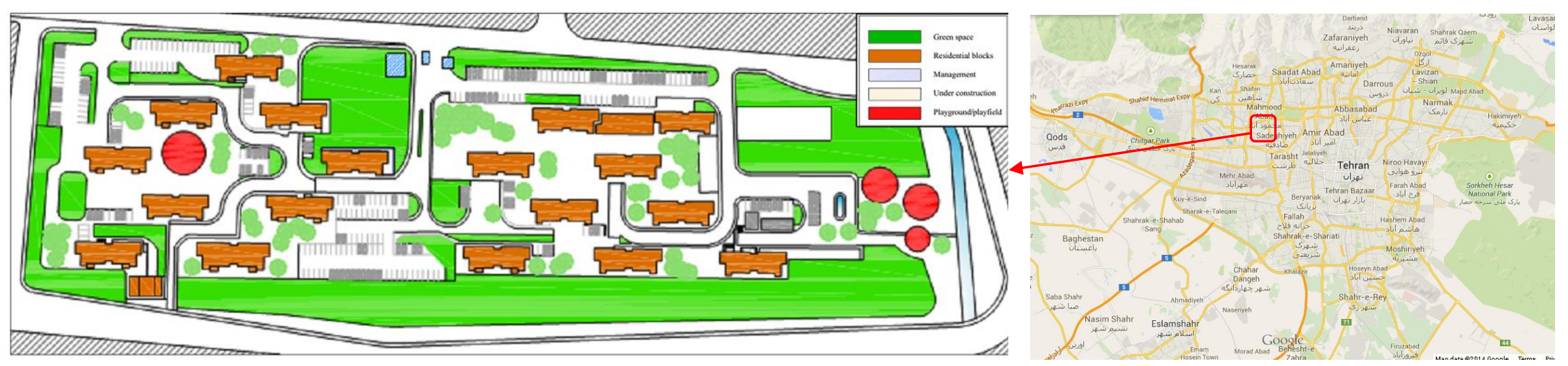




\section{Survey Site}

Data collection from diverse cases offer the capacity to generalise a theory (Yin, 1989), and all researchers in the field of architecture and landscape consider it necessary to choose diverse study cases (Patton, 1990). On the other hand, there are more than 500 residential high-rise complexes, most of which are located in the North and West Zones in Tehran. Therefore, this study seeks to concentrate on these two Zones. Using the information available in the municipality of Tehran, two lists of high-rise apartments in the North and West Zones were prepared, and one residential high-rise apartment randomly selected from each list of high-rises. Those are Sobhan from North Zones and Pas from West Zones. Both cases are explained as follows

\section{Sobhan Apartments}

Sobhan high-rise apartment complex is located in the North Zone of Tehran. It has twelve blocks of 15 floors and altogether there are 1026 apartment units in the complex. The apartment area covers approximately 7.8-Hectares (Figure 1).

At present, Sobhan apartment complex has about 3,600 residents and the complex open spaces consist of three children's playgrounds, landscape, and garden areas. Benches are available throughout the open spaces but no specific areas are designed for adults or parents to sit, gather for interaction with others and accompany their children. They can only sit in every block's lobby or sparsely distributed benches on the site plan, to interact with neighbours. In addition, some body-building equipment has been installed at the site; occasionally this is also used by children.

\section{Pas Apartment}

Pas high-rise apartment's complex is located in the West Part of Tehran. Pas complex has 18 blocks of 16 stories. Altogether, 576 apartment units cover about 5.2 Hectares (Figure 2).

At presently, Pas complex has about 2,100 residents. Similar to Sobhan apartment complex, Pas also has three children's playgrounds; landscape and garden spaces with bench seating spread throughout the site. However, some of the seating areas are clustered together at certain corners of open spaces. Consequently, in Pas complex, there are enough spaces for adults or parents to sit whilst accompanying their children as well as interacting with neighbours. In addition, Pas complex also has sport facilities including a playing field for basketball and volleyball. Furthermore, and similar to Sobhan complex, bodybuilding equipment was installed by the management in the west of the site.

To administer the survey of adult opinions, the aid of the apartment managements was used. For each apartment block (for each complex), two architectural bachelor students were appointed as enumerators. Every working day, the sites were visited and the survey was carried out from 4 PM to 8 or 9 PM, considering the participants' rest or free time after work. Altogether, from two site studies within 27 working days, 470 adults took the questionnaires, but only 261 participants surveyed via questionnaire. This number was sufficient for a strong statistical analysis, because 55.53\% of adults participated in the survey (Mitra and Lankford 1999). Table 1 shows the distribution, frequency and percentage of respondents who participated in this study. The frequency and distribution regarding the gender of respondents was almost equal; however, more females $(54.4 \%, \mathrm{~N}=142)$ were interested in participating than male $(43.3 \%, \mathrm{~N}=113)$. Table 1 show that the highest proportion of the participants belongs to the age range of 30 to 39 years old $(36.8 \%, \mathrm{~N}=96)$, followed by 40 to 49 years old $(26.4 \%, \mathrm{~N}=69)$. The lowest rate of participation was observed in the age group of 50 and above $(13.8 \%, \mathrm{~N}=36)$ followed by those in the age range of 20 to $29(20.7 \%, \mathrm{~N}=54)$. This indicated that most of the participants belonged to people between 30 and 49 years of age 
Sharghi, A., Maulan, S. B., Salleh, I. B., Salim, A. S. B S., Sedghpour, B. S.: Evaluation of Parental Satisfaction of Children's Spaces within High Rise Apartment Environments

$(63.2 \%, \mathrm{~N}=165)$. Furthermore, 53.4\% of Pas residents are between 30 and 39 years old, but only $23.1 \%$ of Sobhan residents are in the same category. Therefore, Pas residents are younger than those living in Sobhan. Table 1 shows that $51.3 \%$ of participants $(\mathrm{N}=134)$ have children and $41.4 \%$ of them $(\mathrm{N}=108)$ do not have any. Furthermore, there is an important difference between the two cases of participants; while $70.3 \%$ of Pas residents have children, only $35.7 \%$ of Sobhan residents have children. It is noteworthy that only $1.7 \%$ of Pas residents did not answer this item, whereas $11.9 \%$ of Sobhan residents had no reply to this question; this is because most Sobhan residents are elderly and have adult children, who either are married or live separately, and the participants could not mention them.

Therefore, in continuation, we used answers provided by adult participants that currently had small children, rather than all adult participant answers, in Results and Discussion sections.

Table 1: Descriptive Statistic of Participants Background

\begin{tabular}{|c|c|c|c|c|c|c|}
\hline \multirow[b]{2}{*}{ Demographic items } & \multicolumn{2}{|c|}{ Sobhan } & \multicolumn{2}{|c|}{ Pas } & \multicolumn{2}{|c|}{ Total } \\
\hline & Frequency & $\begin{array}{c}\text { Percent } \\
(\%)\end{array}$ & Frequency & $\begin{array}{c}\text { Percent } \\
(\%)\end{array}$ & Frequency & $\begin{array}{c}\text { Percent } \\
(\%)\end{array}$ \\
\hline \multicolumn{7}{|l|}{ Gender } \\
\hline Male & 63 & 44.1 & 50 & 42.4 & 113 & 43.3 \\
\hline Female & 77 & 53.8 & 65 & 55.1 & 142 & 54.4 \\
\hline No reply & 3 & 2.1 & 3 & 2.5 & 6 & 2.3 \\
\hline \multicolumn{7}{|l|}{ Age } \\
\hline 20-29 Ages & 33 & 23.1 & 21 & 17.8 & 54 & 20.7 \\
\hline 30-39 Ages & 33 & 23.1 & 63 & 53.4 & 96 & 36.8 \\
\hline 40-49 Ages & 37 & 25.8 & 32 & 27.1 & 69 & 26.4 \\
\hline 50 and above & 36 & 25.2 & 0 & 0 & 36 & 13.8 \\
\hline No reply & 4 & 2.8 & 2 & 1.7 & 6 & 2.3 \\
\hline \multicolumn{7}{|l|}{ Parents/No Parents } \\
\hline Yes & 51 & 35.7 & 83 & 70.3 & 134 & 51.3 \\
\hline No & 75 & 52.4 & 33 & 28 & 108 & 41.4 \\
\hline No reply & 17 & 11.9 & 2 & 1.7 & 19 & 7.3 \\
\hline Total of per Item & 143 & 100 & 118 & 100 & 261 & 100 \\
\hline
\end{tabular}

\section{RESULTS AND DISCUSSION}

The questions were related to satisfaction and preference for open spaces, and participants' perception of safety is explained as follows.

\section{Participant Satisfaction for Open Spaces}

Adults were asked 13 closed-ended questions by using the 4 point Likert scale, $(1=$ Not satisfied, $2=$ Some satisfied, $3=$ Satisfied and $4=$ Very much satisfied) (Cummins \& Gullone, 2000). All items are categorised with mean scores in Table 2.

Furthermore, to understand the underlying cause behind the satisfaction item ranking, confirmatory factor analysis was carried out and revealed four pre-satisfaction dimensions (Table 3). In this study, soft landscapes are live elements in landscapes, like trees, shrubs, flowers, and so on. 
Table 2: Participants' Satisfaction for High Rise Open Spaces

\begin{tabular}{|c|l|c|c|c|}
\hline \multicolumn{2}{|l|}{$\begin{array}{l}\text { I am satisfied with ... } \\
\text { in my high-rise apartments open space. }\end{array}$} & N & Mean & SD \\
\hline 1 & Shrubs and flowers & 256 & 2.87 & 0.95 \\
\hline 2 & Large and Shady Trees & 255 & 2.66 & 1.01 \\
\hline 3 & Green Space Lawn & 258 & 2.64 & 1.08 \\
\hline 4 & Area for Reading and Relax & 254 & 2.22 & 0.87 \\
\hline 5 & Area for Socialisation & 251 & 2.22 & 0.93 \\
\hline 6 & Condition of Walking & 252 & 2.16 & 1.03 \\
\hline 7 & Areas for Observe Children & 246 & 1.72 & 0.79 \\
\hline 8 & View to Water & 231 & 1.67 & 0.86 \\
\hline 9 & Body Practice Tools & 242 & 1.64 & 0.93 \\
\hline 10 & Sports Areas & 249 & 1.59 & 0.87 \\
\hline 11 & Diversity of Facilities & 257 & 1.59 & 0.82 \\
\hline 12 & Children Activity Spaces & 246 & 1.57 & 0.76 \\
\hline 13 & Children Playgrounds & 248 & 1.56 & 0.81 \\
\hline
\end{tabular}

Table 3: Satisfaction Dimensions Analysis

\begin{tabular}{|l|c|c|c|c|}
\hline \multicolumn{1}{|c|}{ Dimension of Satisfactions } & $\begin{array}{c}\text { Loading } \\
\text { factor }\end{array}$ & Mean & SD & Alpha \\
\hline D1. Soft Landscapes & & 2.73 & 0.85 & 0.78 \\
\hline Green Space Lawn & 0.92 & & & \\
\hline Shrubs and Flowers & 0.90 & & & \\
\hline Large and Shady Trees & 0.55 & & & \\
\hline D2. Social Spaces & & 2.21 & 0.74 & 0.69 \\
\hline Condition of Walking & 0.47 & & & \\
\hline Area for Relaxation & 0.78 & & & \\
\hline Area for Socialisation & 0.85 & & & \\
\hline D3. Children Areas & & 1.60 & 0.63 & 0.71 \\
\hline Children Playgrounds & 0.88 & & & \\
\hline Children Activity Spaces & 0.71 & & & \\
\hline Areas for Observe Children & 0.55 & & & \\
\hline D4. Recreational Spaces & & 1.60 & 0.70 & 0.72 \\
\hline Diversity of Facilities & 0.53 & & & \\
\hline Sports Areas & 0.84 & & & \\
\hline Body Practice Tools & 0.81 & & & \\
\hline
\end{tabular}

According to the results, participants express high satisfaction for soft landscape components $($ Mean $=2.73, \mathrm{SD}=0.85$, Alpha $=0.78)$, followed by social spaces $($ Mean $=$ $2.21, \mathrm{SD}=0.74$, Alpha $=0.69)$, children's playgrounds $(\mathrm{Mean}=1.60, \mathrm{SD}=0.63$, Alpha $=$ $0.71)$ and recreation spaces $($ Mean $=1.60, \mathrm{SD}=0.70$, Alpha $=0.72)$. The above-mentioned finding draws emphasis on studies by researchers such as Lee \& Ellis et al. (2008), Alfonzo \& Boarnet et al. (2008), He (2009), Talib (2009), Berkoz \& Turk et al. (2009), Jim \& Chen (2010), Veitch \& Timperio et al. (2011), and Teck-Hong (2012), respectively; that they stated the soft landscape components - like trees, shrubs, flowers, water performance, presence of greenery - have more effects on adults and participant satisfaction from open space than other factors, such as social and recreational spaces. 
Sharghi, A., Maulan, S. B., Salleh, I. B., Salim, A. S. B S., Sedghpour, B. S.: Evaluation of Parental Satisfaction of Children's Spaces within High Rise Apartment Environments

\section{Preferences for Open Spaces}

To understand the relationship between participants' satisfaction and their preferences for open spaces, this study measured their preferences. They were asked to rate their preferences for 11 landscape elements by using the 4 points Likert scale $(1=$ Not Agree, 2 = Somewhat Agree, $3=$ Agree and $4=$ Much Agree $)$. The tabulation of mean scores is presented in Table 4.

The results show that participants had a high preference to sports areas (Mean $=3.62$, $\mathrm{SD}=0.71)$, pathways $($ Mean $=3.47, \mathrm{SD}=0.81)$, shrubs and flowers $($ Mean $=3.48$, $\mathrm{SD}=0.83)$ and fitness equipment $($ Mean=3. 30 and $\mathrm{SD}=1.04)$ in their high-rise apartment areas (Table 4). Presumably, their open spaces lack those facilities. It is surprising to note that large and shady trees (Mean $=3.08 ; \mathrm{SD}=0.95)$ and view to the water $(\mathrm{Mean}=2.96$, $\mathrm{SD}=1.07)$ are not rated highly as preferences, because participants consider their open spaces to already have sufficient facilities.

Table 4: Preference forOpen Spaces Elements

\begin{tabular}{|c|l|c|c|c|}
\hline \multicolumn{2}{|l|}{$\begin{array}{l}\text { I prefer to have } \ldots \\
\text { in my high-rise apartments open space. }\end{array}$} & N & Mean & SD \\
\hline 1 & Sports Areas & 258 & 3.62 & 0.71 \\
\hline 2 & Pathways & 253 & 3.47 & 0.81 \\
\hline 3 & Shrubs and Flowers & 255 & 3.48 & 0.83 \\
\hline 4 & Fitness equipment & 256 & 3.30 & 1.04 \\
\hline 5 & Sitting and Resting Areas & 257 & 3.18 & 0.92 \\
\hline 6 & Large and Shady Trees & 257 & 3.08 & 0.95 \\
\hline 7 & Cycling Paths & 253 & 3.05 & 1.08 \\
\hline 8 & Jogging Paths & 256 & 3.07 & 1.04 \\
\hline 9 & View to the Water & 257 & 2.96 & 1.07 \\
\hline 10 & Maze Routes & 249 & 2.90 & 1.02 \\
\hline 11 & Sandy Areas like Beach & 247 & 2.14 & 1.18 \\
\hline
\end{tabular}

Furthermore, to understand the overall relationship between satisfaction dimension (soft landscapes, children's areas, social and recreational spaces) and independent variables for open space, regression analysis (enter and backward method) was performed. This method is frugal and does not include many additional variables which contribute little to the prediction (Hinton, 2004). In this process, all items of perceived safety and preferences for open space were entered into the backward regression model, to identify items that were confirmed to be related to a particular satisfaction. The results showed this process for satisfaction for soft landscape component items and preferences (Table 5). Based on the results, the $\mathrm{R}^{2}$ value for the model is 0.142 . This means that the results explained $14 \%$ of the phenomenon, and the model has a significance of $\mathrm{F}_{13.1}, \mathrm{P}<0.05$. It reveals that the factor of shrubs and flowers predicts positive satisfaction of soft landscapes $(\beta=0.300)$, whereas other factors including sandy areas like beaches $(\beta=-0.165)$ and view to the water $(\beta=-0.128)$, predicts significantly negative satisfaction of soft landscapes.

The results show that some landscape components, namely shrubs and flowers, are able to satisfy participants from soft landscape components in open space. However, sandy areas like beaches and view to the water are unable to do so, and make participants dissatisfied. 
Table 5: Multiple Regression Result (Backward) between Preference Items and Satisfaction from Soft Landscape Components

\begin{tabular}{|c|l|c|c|c|}
\hline \multirow{2}{*}{ Model } & $\begin{array}{c}\text { Standardized } \\
\text { Coefficients }\end{array}$ & \multirow{2}{*}{ Sig. } & \multirow{2}{*}{ F } \\
\cline { 3 - 3 } & Beta & & \\
\hline & (Constant) & & 0.00 & 8.32 \\
\hline 1 & Shrubs and flowers & .300 & 0.00 & \\
\hline 2 & Sandy areas like beaches & -.165 & 0.01 & \\
\hline 3 & View to the water & -.128 & 0.04 & \\
\hline $\mathbf{R}^{2}$ & \multicolumn{3}{|l}{} \\
\hline
\end{tabular}

Dependent variable: satisfaction for soft landscape components

Predictors (constant): 1. Shrubs and flowers, 2. Sandy areas like beach,

3. View to the water

The above-mentioned process was carried out for another three-satisfaction dimension, respectively. Regarding dimension of social spaces, the results provided a $\mathrm{R}^{2}$ value equal to 0.042 for the model, that explained only $4 \%$ of phenomenon, and the model has a significance of $\mathrm{F}_{10.3}, \mathrm{P}<0.05$. It is a weak model and reveals that only the amenity of cycling paths $(\beta=-0.205)$ predicts negative satisfaction of social spaces. This is because cycling paths cannot make participants from social spaces satisfied in open space, due to the fact they are afraid of children being injured because of cycling outdoors (Rosen \& Peterson, 1990; Prezza \& Alparone et al., 2005; Carver \& Timperio et al., 2008; Bringolf-Isler \& Grize et al., 2010).

Regarding children's play areas, the results calculated the $\mathrm{R}^{2}$ value for the model to be 0.098 ; this means the model explained $10 \%$ of phenomenon and has a significance of $\mathrm{F}_{6.00}$, $\mathrm{P}<0.05$ (Table 6). It reveals that the amenity of sitting and resting areas predicts satisfaction from children's areas positively $(\beta=0.196)$, whereas other amenities including jogging paths $(\beta=-0.206)$ and Pathways $(\beta=-0.136)$, are significant negative predictors of satisfaction of children's areas. Therefore, sitting and resting areas can satisfy participants about children's areas in open space because adults, especially those who have children, can use sitting and resting areas to observe and control their children. This is supported by Hiscock et al. (2008), who argued play areas that are controllable by participants can satisfy them, and facilitate more associations between children and high physical activities. However, this is not the case when people use pathways and jogging paths.

Table 6: Multiple Regression Result (Backward) between Preference Items and Satisfaction from Children's Areas

\begin{tabular}{|c|c|c|c|c|}
\hline \multirow{2}{*}{\multicolumn{2}{|c|}{ Model }} & $\begin{array}{c}\text { Standardised } \\
\text { Coefficients }\end{array}$ & \multirow[t]{2}{*}{ Sig. } & \multirow[t]{2}{*}{$\mathbf{F}$} \\
\hline & & & & \\
\hline & (Constant) & & 0.00 & 6.44 \\
\hline 1 & Sitting and Resting Areas & .196 & 0.00 & \\
\hline 2 & Jogging Paths & -.206 & 0.00 & \\
\hline 3 & Pathways & -.136 & 0.04 & \\
\hline $\mathbf{R}^{2}$ & \multicolumn{4}{|c|}{$10 \%$} \\
\hline
\end{tabular}

Dependent variable: satisfaction from children's areas

Predictors (constant): 1. Large and Shady Trees, 2. Sitting and Resting Areas,

3. Jogging Paths, 4. Pathways 
Sharghi, A., Maulan, S. B., Salleh, I. B., Salim, A. S. B S., Sedghpour, B. S.: Evaluation of Parental Satisfaction of Children's Spaces within High Rise Apartment Environments

Regarding dimension of recreational spaces, the results produced an $\mathrm{R}^{2}$ value for the model equal to 0.050 , explaining only $5 \%$ of the phenomenon. Therefore, the model is significant to $\mathrm{F}_{11.9}, \mathrm{P}<0.05$. It is a weak model, and reveals that only the amenity of jogging paths $(\beta=-0.224)$ predicts satisfaction of recreational spaces negatively. This is because jogging paths are unable to satisfy the participants of recreational spaces, due to concerns children could be injured there.

\section{Perception of Safety}

In addition to preferences for open spaces, this study is also interesting to test the relationship between adults' satisfaction for open spaces and perceived safety of open space. Participants were asked to rate their agreement about safety of open spaces with nine closed-ended statements, using the 4 points Likert Scale $(1=$ Not Agree, $2=$ Somewhat Agree, 3 = Agree and $4=$ Much Agree). The description of the statements is illustrated in Table 7.

The results show that parents are very concerned about their children having an accident in the open spaces $($ Mean $=2.64, \mathrm{SD}=1.14)$, followed by the presence of visually obscured places $($ mean $=2.64, \mathrm{SD}=1.09)$. However, they are less concerned about dirty and unsanitary materials in open spaces. Accordingly, they perceived open spaces to be clean $($ Mean $=1.39, \mathrm{SD}=0.70)$.

\section{Table 7: Perceived Safety of High Rise Open Space}

\begin{tabular}{|c|l|c|c|c|}
\hline \multicolumn{2}{|l|}{$\begin{array}{l}\text { How much are you agree with ... } \\
\text { in your high-rise apartments open space }\end{array}$} & N & Mean & SD \\
\hline 1 & Children May Have Accident & 250 & 2.64 & 1.14 \\
\hline 2 & Visually Obscured Places & 241 & 2.64 & 1.09 \\
\hline 3 & Crowded Open Space & 239 & 2.28 & 1.00 \\
\hline 4 & Bad Spatial Arrangement & 238 & 2.25 & 1.05 \\
\hline 5 & Invisible Children Playground & 250 & 2.17 & 1.09 \\
\hline 6 & Far from Window's View & 223 & 2.13 & .98 \\
\hline 7 & Children May Have Injury & 234 & 1.98 & 1.08 \\
\hline 8 & Darkness at Evening and Early Night & 250 & 1.92 & .82 \\
\hline 9 & Dirty and Unsanitary Materials & 243 & 1.39 & .70 \\
\hline
\end{tabular}

Likewise, to understand the relationship between satisfaction dimensions (soft landscapes, children's areas, social and recreational spaces) with the participants' perception of safety for open space, regression analysis was performed. The results displayed in Table 8 show that satisfaction for perceived safety of soft landscape components provided a $\mathrm{R}^{2}$ value for the model equal 0.188 , that explained $19 \%$ of phenomenon, and the model is significant to $\mathrm{F}_{12.0}, \mathrm{P}<0.05$.

Results reveal that three safety component factors, namely visually obscured places $(\beta=-0.205)$, dirty and unsanitary materials $(\beta=-0.269)$ and bad spatial arrangement $(\beta=-0.150)$. predicts significantly negative satisfaction of soft landscapes. In contrast, the factor of crowded open space $(\beta=0.193)$ predicts significantly positive satisfaction of soft landscapes. The results showed crowding of open space gives adults a positive effect on their satisfaction of soft landscapes. 
Table 8: Multiple Regression Result (Backward) between Perception of Safety Items and Satisfaction of Children's Areas

\begin{tabular}{|c|c|c|c|c|}
\hline \multicolumn{2}{|r|}{ Model } & $\begin{array}{c}\text { Standardized } \\
\text { Coefficients }\end{array}$ & Sig. & $\mathbf{F}$ \\
\hline & (Constant) & & 0.00 & 6.44 \\
\hline 1 & Crowded Open Space & .193 & 0.00 & \\
\hline 2 & Visually Obscured Places & -.205 & 0.00 & \\
\hline 3 & Dirty and Unsanitary Materials & -.269 & 0.00 & \\
\hline 4 & Bad Spatial Arrangement & -.150 & 0.02 & \\
\hline$\overline{\mathbf{R}^{2}}$ & & $9 \%$ & & \\
\hline
\end{tabular}

Dependent variable: satisfaction from children's areas

Predictors (constant): 1. Open Space Is Crowded, 2. Invisible Places

3. Dirty and Unhealthy Materials and 4. Bad Spatial Arrangement

Regarding children's areas, the model produced an $\mathrm{R}^{2}$ value of 0.174 ; meaning the model explained $17 \%$ of phenomenon, and is significant to $\mathrm{F}_{3.23}, \mathrm{P}<0.05$. It reveals that the factor of children may have accident $(\beta=-0.140)$, predicts significantly negative satisfaction of children's areas. Therefore, it presumes that the risk of accidents between cars and children makes participants worry about open spaces.

Regarding dimension of social spaces, the results produced an $\mathrm{R}^{2}$ value for the model equal to 0.237 , that explained $24 \%$ of phenomenon and the model is significant to $\mathrm{F}_{6.23}, \mathrm{P}<0.05$. With this model the factors of darkness at evening and nighttime $(\beta=-0.199)$ and visually obscured children's playground $(\beta=-0.137)$ predict negative satisfaction of social spaces. Consequently, adult participants satisfied from social spaces are afraid of children being injured in open spaces, due to unsupervised and visually obscured areas (Rosen and Peterson 1990, Prezza, Alparone et al. 2005, Carver, Timperio et al. 2008, Bringolf-Isler, Grize et al. 2010).

Concerning dimension of recreational spaces, the results provided an $\mathrm{R}^{2}$ value for the model equal to 0.320 , explaining only $5 \%$ of the phenomenon. Therefore, the model is significant to $\mathrm{F}_{5.79}, \mathrm{P}<0.05$. It reveals that the probability of children being injured $(\beta=-0.188)$, and children having an accident $(\beta=-0.154)$, and predicts negative satisfaction of recreational spaces.

\section{CONCLUSIONS}

The satisfaction gained from open spaces associated with high-rise apartments is the dependent variable in this study. We tested satisfaction in four dimensions, namely soft landscapes, children's areas, social spaces, and recreational spaces. The findings of this paper suggest that open space and soft landscape components are more important to the participants than recreational spaces, children's areas and social spaces. Participants are also satisfied with social spaces; however, they had least satisfaction regarding children's playgrounds and recreation spaces, preferring the soft landscape components more than factors such as sitting and rest areas, large and shady trees, cycling and jogging paths, view of the water, and maze routes in open spaces. Furthermore, participants are agreeing with most safety factors, but have anxiety regarding children being injured within open spaces. In addition, the parents who can directly observe the playgrounds from apartments have higher satisfaction relating to soft landscape within their open spaces (Tables 7 and 8, respectively). Finally, findings 
Sharghi, A., Maulan, S. B., Salleh, I. B., Salim, A. S. B S., Sedghpour, B. S.: Evaluation of Parental Satisfaction of Children's Spaces within High Rise Apartment Environments

revealed that adults without children have a higher satisfaction of soft landscapes within their open spaces, because they are less concerned with a lack of soft landscapes in open spaces.

The results showed that the participants' satisfaction of open space, in relation to soft landscape components, is more significant than the satisfaction from recreational spaces, social spaces and children's areas. Therefore, it is demonstrated that soft landscape components such as trees, shrubs and flowers, and recreational spaces such as playing fields, increase participant satisfaction more than both social spaces and children's areas. On the whole, a previous study supported some of the above-mentioned findings; that every soft landscape component such as trees (types, size and shape of them), shrubs, flowers, water performance, presence of greenery, have more effects on resident's satisfaction from open space, than other factors such as social and recreational spaces (Kaplan \& Kaplan et al., 1998, Bird, 2007; Lee \& Ellis et al., 2008; Matsuoka \& Kaplan, 2008; Hur \& Nasar et al., 2010).

This study has a significant finding about participant's satisfaction concerning open spaces. In addition, their satisfaction was discussed in four dimensions, namely soft landscapes, children's areas, social and recreational spaces. Based on the findings of this study, the implications for designing open spaces include the following.

Based on Tehran urban design, open spaces associated with high-rise buildings are to be located between blocks. Therefore, it is preferred that soft landscapes are situated between residential blocks and children's areas, social and recreational spaces. This study highlights the importance of open space around high-rise apartments for children's physical activities. Therefore, children's areas such as playgrounds have to provide sufficient facilities.

It is important to locate the playgrounds close to each block or between blocks, not in the corners or perimeter of the sites, to facilitate accessibility. It is recommended that each playground be visible from apartment unit windows. Parents of small children are worried about distant children's playgrounds when they sit and use social areas. Therefore, the study recommends combining some of the social spaces with children's areas for these adults, during the design process. In addition, their preference for sitting areas and pathways in open space must be taken into account in the design process of open spaces in high-rise residential complexes.

\section{REFERENCES}

Alfonzo, M., Boarnet, M. G., Day, K., Mcmillan T. \& C. L. Anderson (2008). "The relationship of neighbourhood built environment features and adult parents' walking." Journal of Urban Design 13(1): 29-51.

Alton, D., Adab, P., Roberts, L. \& T. Barrett (2007). "Relationship between walking levels and perceptions of the local neighbourhood environment " Archives of Disease in Childhood 92: 5.

Barbel, I. (2000). The psychology of the child. Paris, Presses Universitaires de France.

Berkoz, L., Turk, Ş. Ş. \& Ö. L. Kellekci (2009). "Environmental quality and user satisfaction in mass housing areas: the case of Istanbul."

Bird, W. (2007). Natural Thinking. Royal Society for the Protection of Birds.

Bringolf-Isler, Grize, B. L., Mäder, U., Ruch, N., Sennhauser, F. H. \& C. Braun-Fahrländer (2010). "Built environment, parents' perception, and children's vigorous outdoor play." Preventive medicine 50(5): 251-256.

Carver, A., Timperio, A. \& D. Crawford (2008). "Playing it safe: The influence of neighborhood safety on children's physical activity- A review." Health \& Place 14: 217-227. 
Cummins, R. A., Gullone, E. (2000). Why we should not use 5-point Likert scales: The case for subjective quality of life measurement. Proceedings, second international conference on quality of life in cities.

Deci, E. L., Koestner, R. \& R. M. Ryan (1999). "A meta-analytic review of experiments examining the effects of extrinsic rewards on intrinsic motivation." Psychological bulletin 125(6): 627 .

Gifford, R. (2007). "The consequences of living in high-rise buildings." Architectural science review 50(1): 2-17.

Gordon, J. L. (2009). Thinking about Knowledge Learning and Wisdom, AKRI Limited.

Hagerhall, C. (2000). "Clustering predictors of landscape preference in the traditional swedish cultural landscape: Prospect-refuge, mystery, age and management." Journal of Environmental Psychology 20: 8.

He, X. (2009). Residential satisfaction with home location: Examination of the relationship between location-embedded benefits and risk perception, Texas State University.

Hur, M., Nasar, J. L. \& B. Chun (2010). "Neighborhood satisfaction, physical and perceived naturalness and openness." Journal of Environmental Psychology: 8.

Jim, C., Chen, W. Y. (2010). "External effects of neighbourhood parks and landscape elements on high-rise residential value." Land Use Policy 27(2): 662-670.

Kaplan, R., Kaplan, S. \& R. Ryan (1998). With people in mind: Design and management of everyday nature, Island Press.

Lee, S.-W., Ellis, C. D., Kweonb, B.-S. \& S.-K. Hong (2008). "Relationship between landscape structure and neighborhood satisfaction in urbanized areas." Landscape and Urban Planning (85): 11.

Maslow, A. H., Frager, R. \& J. Fadiman (1970). Motivation and personality, Harper \& Row New York.

Mastura, J., Noorliza, H., Mahamad, O. \& T. Ramayah (2008). "The determinants of housing satisfaction level: A study on residential development project by Penang Development Corporation (PDC)." Malaysia: Universiti Sains Malaysia.

Matsuoka, R. H., Kaplan, R. (2008). "People needs in the urban landscape: Analysis of Landscape And Urban Planning contributions, A Review." Landscape and Urban Planning 84: 13.

Melichar, J., Kaprová, K. (2013). "Revealing preferences of Prague's homebuyers toward greenery amenities: The empirical evidence of distance-size effect." Landscape and Urban Planning 109(1): 56-66.

Mitra, A., Lankford, S. (1999). Research methods in park, recreation and leisure services. Illinois, Sagamore Publishing.

Mnisi-Mudunungu, G. D. (2011). Implementation of government housing delivery programme in the Gravellotte area of Ba-Phalaborwa Municipality, Limpopo, University of Limpopo (Turfloop Campus).

Patton, M. Q. (1990). Qualitative evaluations and research methods. Newbury Park, Sage.

Prezza, M., Alparone, F. R., Cristallo, C. \& S. Luigi (2005). "Parental perception of social risk and of positive potentiality of outdoor autonomy for children: The development of two instruments." Journal of Environmental Psychology 25: 17. 
Sharghi, A., Maulan, S. B., Salleh, I. B., Salim, A. S. B S., Sedghpour, B. S.: Evaluation of Parental Satisfaction of Children's Spaces within High Rise Apartment Environments

Purcell, T., Peron, E. \& R. Berto (2001). "Why do preferences differ between scene types?" Environment and Behavior 33(1): 14.

Rosen, B. N., Peterson, L. (1990). "Gender differences in children's outdoor play injuries: A review and an integration." Clinical Psychology Review 10(2): 187-205.

Rowlands, A. V., Eston, R. G. \& D. K. Ingledew (1999). "Relationship between activity levels, aerobic fitness, and body fat in 8-to 10-yr-old children." Journal of Applied Physiology 86(4): 1428-1435.

Ryan, R. L. (2006). The Role of Place Attachment in Sustaining Urban Parks. The Human Metropolis: People and Nature in the 21st-Century City. R. H. Platt, University of Massachusetts Press: 61-74.

Talib, R. (2009). Residents Satisfaction Survey On The Selected Government's Double Storey Terrace Housing Units At Precinct 9, Federal Territory Of Putrajaya, Malaysia-Precinct With No-Fence Concept.

Tashakkori, A., Teddlie, C. (2003). Handbook of mixed methods in social \& behavioral research, Sage.

Teck-Hong, T. (2012). "Housing satisfaction in medium- and high-cost housing: The case of Greater Kuala Lumpur, Malaysia." Habitat International 36(1): 108-116.

Valentine, G., McKendrick, J. (1997). "Children's Outdoor Play: Exploring Parental Concerns About Children's Safety and the Changing Nature of Childhood." Children's outdoor play: 219-235.

Veitch, J., Salmon, J. \& K. Ball (2008). "Children's active free play in local neighborhoods: a behavioral mapping study." Health education research 23(5): 10.

Veitch, J., Timperio, A., Crawford, D., Pysch, G., Giles-Corti, B. \& J. Salmon (2011). "Is the neighbourhood environment associated with sedentary behaviour outside of school hours among children?" Annals of behavioral medicine 41(3): 333-341.

Weir, L. A., Etelson, D. \& D. A. Brand (2006). "Parents' perceptions of neighborhood safety and children's physical activity." Preventive Medicine: 212-217.

Witten, K., Hiscock, R., Pearce, J. \& T. Blakely (2008). "Neighborhood access to open spaces and the physical activity of residents: A national study." Preventive Medicine: 299-303.

Yang, Q. (2012). "Lively Streets and Better Social Life."

Yin, R. K. (1989). Case Study Research: Design and Methods. Beverley Hills, Sage. 